\title{
IMPACTOS DE EXTRAÇÃO DO PETRÓLEO (ÓLEO E GÁS) NO RIO GRANDE DO NORTE, NA REGIÃO DO ALTO DO RODRIGUES/RN
}

\author{
C. A. V. GURGEL' , G. B. de QUEIROZ' , E. L. S. C. dos SANTOS ${ }^{1}$ e M. L. M. GALVÃO'
}

'Diretoria Acadêmica de Recursos Naturais - Instituto Federal do Rio Grande do Norte cinthya_gurgel@hotmail.com - ecgpfrh@gmail.com

\section{RESUMO}

Este trabalho traz a temática dos impactos gerados pelo desenvolvimento da atividade petrolífera que proporciona tantas riquezas e conflitos. A abordagem é feita em cima dos impactos de extração do petróleo e a utilização do gás, retirado dos poços, na usina de termoelétrica de co-geração do Vale do Açu, Jesus Soares Pereira. Fundamenta-se numa pesquisa bibliográfica e no levantamento de dados em campo. Ela aborda os principais pontos da história, a composição do petróleo, extração, produção, geopolítica e o desenvolvimento da atividade petrolífera no território norte-rio-grandense, com a caracterização do município de Alto do Rodrigues, feita pelo relatório do Serviço Geológico do Brasil (2005), um breve relato sobre o gás natural e a apresentação dos dados que foram coletados durante visita técnica a usina, onde ainda foi observada a importância da atividade para o estado e a preocupação com a questão ambiental e a não emissão de gases tóxicos ou estufa da empresa, que é responsável pela produção do vapor de água, o qual é injetado em outros poços - demonstrando a interação entre a atividade de extração e a geração de energias e riquezas para o estado do Rio Grande do Norte.

\section{IMPACTS OF EXTRACTION OF PETROLEUM (OIL AND GAS) IN RIO GRANDE DO NORTE, IN THE ALTO DO RODRIGUES/RN}

\begin{abstract}
This paper brings the themes of the impact caused by development of the oil activity that provides so many riches and conflicts. The approach is made upon the impacts of oil extraction and utilization of gas from wells in the removed thermal power plant co-generation Vale do Açu, Jesus Soares Pereira. It is based on a literature search and field survey data. It covers the main points of history, the composition of the oil, mining, production, geopolitical and the development of the oil activity in the territory of Rio Grande do Norte, with the characterization of the municipality of Alto do
\end{abstract}

Rodrigues, made by the report of the MRCP (2005), a brief report on natural gas and presentation of data that were collected during the plant technical visit, where noted the importance of activity for the state and concern about environmental issues and no toxic fumes or gases company, which is still responsible for the production of water vapor that is injected in some wells - demonstrating the interaction between the mining activity and the generation of energy and wealth for the territory of Rio Grande do Norte.

KEYWORDS: petroleum in RN, environmental impacts, natural gas in RN, Termoaçu. 


\section{IMPACTOS DE EXTRAÇÃO DO PETRÓLEO (ÓLEO E GÁS) NO RIO GRANDE DO NORTE, NA REGIÃO DO ALTO DO RODRIGUES/RN}

\section{INTRODUÇÃO}

O presente trabalho discorre sobre o processo produtivo do petróleo, visando a extração e os impactos decorrentes dele, disponibiliza conhecimento no tocante a origem e composição do petróleo, que configuram um embasamento necessário para discussões sobre as questões ambientais - principalmente as do território potiguar -, além das noções sobre a história, a representatividade e o desenvolvimento da atividade no Rio grande do Norte, com destaque para o município de Alto do Rodrigues, sede da usina de termoelétrica de co-geração do Vale do Açu, Jesus Soares Pereira, que está atrelada a atividade petrolífera da região. Esta pesquisa foi fomentada pelo Programa de Formação de Recursos Humanos da PETROBRAS (PFRHPETROBRAS), que estimula jovens a pesquisarem sobre energias e biocombustíveis a fim de despertar o interesse sobre a temática.

A fim de se alcançar os objetivos determinados, obteve-se o conhecimento por meio da literatura disponibilizada, que trouxe dados da história e configuração da problemática, além de apresentar o produto gerado. Em seguida foi realizada uma visita técnica a Usina Termoelétrica do Vale do Açu, que proporcionou a coleta de informações, além da realização de entrevistas; a participação em aulas dialogais, os grupos de estudo e os seminários também auxiliaram na confecção do artigo. Por fim, o PFRH disponibilizou um minicurso de geoprocessamento para subsidiar a pesquisa no seu caráter gráfico.

Como a pesquisa encontra-se em desenvolvimento, ainda está se trabalhando no destaque para os impactos de extração e produção de petróleo em território potiguar, mas a literatura até agora levantada que relata a utilização do gás na TERMOAÇU está presente no corpo do artigo.

O trabalho inicia apresentando os principais pontos da história mundial do petróleo, bem como traz sua origem e composição para auxiliar no entendimento posterior do desenvolvimento da atividade. Em seguida é apresentada a forma mais usual de produção na área de Alto do Rodrigues, a produção por bombeio mecânico, ou "cavalo-de-pau".

Os impactos ambientais vêm logo em seguida, uma vez que os questionamentos sobre essa fonte de energia primária na atualidade se fazem presentes de forma recorrente em noticiários e convenções. Com uma visão que leva em conta o conceito de sustentabilidade e de impacto ambiental, é apresentado um dos principais impactos da atividade petrolífera, que a contaminação da água injetada nos poços para melhorar a produção.

Após os impactos, a atividade petrolífera é caracterizada no RN pela história e representatividade no $\mathrm{RN}$, a apresentação do município de Alto do Rodrigues, e a utilização do gás pela usina com a colocação dos dados da visita - bem como também é feito um breve relato sobre composição e utilização do gás natural.

Por fim, as considerações finais trazem o pensamento referente à atividade no Rio Grande do Norte que pode ser extraído com a leitura, bem como demonstra a preocupação com o desenvolvimento sustentável da atividade de extração do petróleo e da utilização do gás natural. 


\section{PETRÓLEO: ORIGEM E HISTÓRIA}

Com o caminhar da humanidade não só se evolui no conhecimento, mas também cresce o consumo. E, para sustentar esse consumismo, a procura por mais reservatórios da principal fonte primária de energia da modernidade, o petróleo, cresce, além da busca por novas tecnologias, adaptações e aperfeiçoamento.

O petróleo está presente em vários itens do cotidiano das pessoas e da indústria, como combustíveis, fertilizantes e petroquímicos, que substituem uma grande parte de matériasprimas, como vidro, metais, celulose e até mesmo as de origem animal, como lã, marfim e couro. Ele é sinônimo de riqueza e poder para um país e se tornou mais valorizado ainda com a criação da OPEP (Organização dos Países Exportadores de Petróleo), pois não só garante o desenvolvimento da indústria, do transporte e da segurança, como também é imprescindível para a estabilidade de grandes potências mundiais, como Estados Unidos, China, Rússia, Brasil, Venezuela, entre outros. E, como todo tesouro, foi o motivo de várias guerras: a Primeira Guerra do Golfo, a Guerra Irã-Iraque, a luta pela independência da Chechênia e a invasão estadunidense no Iraque, em 2003.

\subsection{Origem}

O petróleo é um composto viscoso de Carbono e Hidrogênio (hidrocarbonetos alifáticos, alicíclicos e aromáticos) com pequenas porções de Oxigênio, Nitrogênio e Enxofre, de coloração que varia entre o negro e o âmbar, além de menos denso que a água. Pode ocorrer no estado sólido, em que é conhecido como asfalto, no estado líquido, denominado de óleo cru, e no estado gasoso, como gás natural.

As bacias sedimentares, que constituem $64 \%$ da estrutura geológica das terras emersas brasileiras, consoante Moreira \& Sene (2005, p. 84), são depressões de relevo preenchidas por fragmentos de rochas preexistentes, que foram erodidas, e grande quantidade de organismos animais e vegetais depositados, lentamente, em um grande intervalo de tempo geológico e que por meio da compactação ou cimentação ocasionadas pelo emparelhamento das camadas geológicas, calor e pressão transformam-se em combustíveis fósseis. A maioria dos hidrocarbonetos explorados mundialmente vem de rochas sedimentares. Além da matéria orgânica e das transformações termoquímicas, para que o petróleo (óleo e gás) venha a se formar, também é preciso outras condições iniciais, como o afastamento das bactérias aeróbicas, a imobilidade do material orgânico por um longo período e a presença de bactérias anaeróbicas. O petróleo então formado migra pelos poros da rocha para locais de menor pressão e vem a superfície ou para em uma camada impermeável, onde será armazenado.

As áreas mais propícias à formação de petróleo são mares interiores, baías e golfos, sendo a ocorrência de reservas nos interiores dos continentes resultantes de áreas originalmente marinhas, emergidas por forças advindas dos movimentos da crosta, ou da migração do óleo das rochas geradoras para as rochas armazenadoras por meio de fendas.

Com relação à idade dos sedimentos, $60 \%$ do petróleo e do gás encontrado são originários de estratos do período cenozóico, conforme Corrêa (2003, p. 14), sendo as principais reservas 
petrolíferas datadas do mesozóico (período cretáceo).

\subsection{História}

O primeiro poço de petróleo foi perfurado nos Estados Unidos durante uma busca por água - é comum em algumas regiões norte-americanas a escassez de água -, em 1859. Mas seu uso industrial só se deu na segunda metade do século XIX, em Tittusville pelo Coronel Edwin L. Drake - a produção chegou a 19 barris/dia, Consoante Cúneo (2011, p. 01).

Para conseguir perfurar o poço, o primeiro método utilizado foi o de escavação da terra e para se alcançar rapidamente maiores profundidades o método mais eficaz é o rotativo, onde a coluna de perfuração, tendo na ponta uma broca, vai penetrando no solo - em determinados intervalos retiram-se amostras que vão sendo analisadas no decorrer da operação; algumas vezes a perfuração é feita de maneira direcional para debelar um incêndio ou controle de jorro de petróleo;

A 4000 metros de profundidade, em camadas de rochas sedimentares, o poço sofre uma pressão de mais de 400 atmosferas $\left(400 \mathrm{~kg}\right.$ por $\left.\mathrm{cm}^{2}\right)$ e para equilibrar a pressão interna com a externa é injetada no poço uma mistura especial de lama, argila e água que vai sendo despejada à medida que a sonda se aprofunda. (CÚNEO, 2011, p. 01)

Com relação a esses fluidos, existem variados tipos que, dependendo das propriedades das formações geológicas a serem perfuradas, variam em sua composição química - segundo Corrêa (2003, p. 41), os produtos mais utilizados são: “amidos, carbonatos, soda cáustica, detergentes, ácidos, inibidores de corrosão, cromatos, cloretos, asfaltenos, polifenóis, polímeros, etc". Eles são denominados ainda como lamas de perfuração e são indispensáveis para evitar a entrada de fluídos das formações, a entrada de lascas de rocha no poço - devido à pressão que exercem -, além de resfriarem a broca e trazerem o material perfurado (cascalho) do fundo do poço até a superfície - e assim tal material será analisado por geólogos, o que, mesmo confirmada à inexistência de uma reserva produtiva, contribui para um maior conhecimento e interpretações dessa área explorada.

O primeiro uso do petróleo foi como combustível, em substituição do óleo da baleia na iluminação, por exemplo. Como era muito inflamável ele passou a ser refinado em alambiques, obtendo-se assim, o querosene. A invenção dos motores de explosão e a diesel, em 1887, fez com que as frações do petróleo que eram desprezadas passassem a ter novas aplicações.

No Brasil, já se tinha relatos da utilização do petróleo desde os tempos de imperialismo, onde o Marquês de Olinda cedeu o direito a José Barros de Pimentel de realizar a extração de betume nas margens do rio Marau, na Bahia.

O primeiro reservatório de petróleo brasileiro foi encontrado em 1930 em Lobato, bairro suburbano de Salvador (BA), pelo engenheiro agrônomo Manoel Inácio de Basto, que em 1932 comunicou seu achado ao então presidente da república, Getúlio Vargas.

A descoberta de tal riqueza gerou inúmeras medidas institucionais nessa década e nas décadas posteriores como, em 1938, a discussão sobre o uso e a exploração dos recursos do subsolo brasileiro, que viabilizou a criação do CNP - Conselho Nacional do Petróleo (em suas primeiras ações, o conselho determinou várias diretrizes com respeito ao petróleo e determinou 
que as jazidas pertencessem à União); em 1953, foi estabelecida a oficialização do monopólio estatal sobre a atividade petrolífera e a criação da empresa estatal "Petróleo Brasileiro S.A.", mais conhecida como Petrobras; e na década de 60 aumentou-se o poder econômico da Petróleo Brasileiro S.A. No ano de 1968, a empresa passou a desenvolver um projeto de extração iniciando a exploração de petróleo em águas profundas; em 1974 houve a descoberta dos poços na bacia de Santos, a maior reserva do país, e com o passar dos anos desenvolveu-se tecnologias para a exploração marinha em águas profundas e ultraprofundas, o que tornou o território brasileiro auto-suficiente em petróleo, suprindo, conforme Sousa (2010, p. 01), mais de $90 \%$ da demanda interna de petróleo e seus derivados. Tal conquista proporcionou não só o crescimento econômico, mas também a diminuição do desemprego.

As reservas de petróleo no mega campo de Tupi, na Bacia de Santos, foram descobertas em 2007. O termo pré-sal é a denominação dada pelos geólogos à camada de rochas porosas que se localiza abaixo de uma espessa camada de sal no subsolo marinho. Ela guarda grandes reservatórios de petróleo, numa faixa de $800 \mathrm{~km}$ que vão do estado do Espírito Santo ao de Santa Catarina e a sete (07) mil metros de profundidade, consoante Sousa (2010, p. 01).

Estima-se, ainda, que as jazidas do pré-sal tenham iniciado seu processo de formação a mais de 100 mil anos, quando o super continente Gondwana se separou formando os atuais, mais precisamente durante a separação entre o atual Sul Americano e Africano. O principal desafio à ampliação da extração nessa bacia é o tipo de rocha. Na Bacia de Campos, o principal campo petrolífero brasileiro localizado na camada pós-sal, o óleo está armazenado em rochas com predomínio de silício. No pré-sal, a substância encontra-se armazenada em rochas constituídas principalmente por carbonato de cálcio e magnésio, o que dificulta o trabalho dos geólogos.

\section{PERFURAÇÃO DE POÇOS}

Neste documento será exposta a perfuração de poços onshore, uma vez que a pesquisa se delimita extração em terra.

Após os estudos para a determinação do tamanho da reserva de petróleo e os impactos ambientais que serão gerados, além da posse das licenças para iniciar a atividade, o terreno é limpo, nivelado e são construídas estadas de acesso, uma vez que as sondas terrestres necessitam de tal recurso para poderem ser transportadas - como as sondas que perfurarão necessitam em locais de difícil acesso, como ilhas e florestas, de helicópteros e embarcações.

A perfuração só termina quando é atingida a profundidade determinada nos estudos geológicos feitos durante a exploração.

Como nessas perfurações um dos itens de extrema importância são os fluidos, ou lama, de perfuração, faz-se necessária a existência de fontes d'água nas proximidades. Se elas não existirem naturalmente, a equipe se encarregará de cavar poços d'água para essa produção de águas subterrâneas. Essa lama é injetada no poço por meio de canais dentro da estrutura das brocas, o que auxiliará não só na retirada dos cascalhos, mas também na perfuração, uma vez que se calcula a melhor hidráulica para aumentar o impacto dos jatos sobre a estrutura.

As características que fluidos de perfuração devem possuir são:

- Refrigerar as brocas de perfuração. 
- Ter uma viscosidade suficiente para arrastar os cascalhos formados ao fundo do poço para a superfície.

- Possuir uma tensão superficial e densidade suficiente para manter em suspensão os cascalhos contidos na lama durante a paralisação da perfuração, enquanto se fazem as conecções do dos tubos, durante a perfuração.

- Ter um peso suficiente para manter a pressão hidrostática da lama equivalente à pressão das formações atravessadas, evitando a ocorrência de erupções (kicks ou blowouts) durante o avanço da perfuração.

- Não alterar as suas características com o aumento da temperatura do fundo do poço à medida que a perfuração prossegue.

- Não penetrar, através de seu filtrado (líquido que a lama perde entre o poço e as formações), nas formações que estejam sendo perfuradas. (CORRÊA, 2003, p. 41)

Devido sua extrema importância, existem muitas empresas que se encarregam dos estudos sobre essas lamas, e da fabricação de alguns produtos especiais e/ou do próprio fluido, bem como acompanham as características dele na utilização.

Como aqui já foi exposto, há vários tipos de lamas de perfuração, e para o desenvolvimento de uma atividade podem ser usados mais de um tipo de fluido:

\begin{abstract}
Assim, temos: as lamas a base de água (as mais comuns na perfuração das formações superficiais); as de base óleo, hoje evitadas, devido aos problemas ambientais; as de base em soluções catiônicas, atualmente muito utilizadas, devido à estabilidade de suas características; as de base cal, muito utilizadas na perfuração de calcáreos; e muitas outras. (CORRÊA, 2003, p. 41)
\end{abstract}

A água é a fase contínua e o principal componente dos fluidos a base da água, ou aquosos. Eles são relativamente mais baratos e biodegradáveis, porém possuem limitações técnicas e operacionais para a execução da atividade.

A fim de suprir as lacunas deixadas pelos fluidos aquosos, desenvolveu-se como alternativa, os fluidos sintéticos, que tem como base a parafina - óleo altamente hidratado -, além de outros adicionais químicos.

Para o descarte dos fluidos de perfuração, que trazem os cascalhos, além dos cortes de rocha, a equipe cava um fosso reserva que será revestido com plástico. Caso a área seja de risco, como pântanos e regiões selvagens, esse material deve ser descartado com o auxílio de caminhões em outros locais.

Assim, são escavados vários tipos de poços, além dos que aqui já foram citados, e que recebem denominações conforme sua finalidade:

- Poço pioneiro. É o primeiro poço perfurado na área.

- Poço estratigráfico. É aquele perfurado para melhor conhecimento da superfície. 
- Poço de extensão. É o poço que irá determinar o tamanho da jazida de petróleo encontrada.

- Poço pioneiro adjacente. É aquele perfurado próximo ao primeiro poço da área.

- Poço perfurado para a jazida mais rasa do reservatório.

- Poço perfurado para a jazida mais profunda do reservatório.

- Poço de desenvolvimento. É o poço perfurado para desenvolver um campo de petróleo.

- Poço de injeção. É aquele destinado a injetar fluidos dentro do reservatório, para estimular sua produção.

- Poço d'água. Destina-se a produção de águas subterrâneas. (CORRÊA, 2003, p. 21 )

Após essa primeira fase de preparação, a sonda terrestre é instalada. As sondas de perfuração são constituídas de três sistemas indispensáveis, e outros dois, que não se fazem essenciais. Tais sistemas são, consoante Corrêa, respectivamente: o sistema de elevação; o sistema de circulação; o sistema de rotação; o sistema de compensação de ondas (que é destinado a plataformas em alto mar, e que por isso não será mencionado mais adiante) e; o sistema de prevenção de erupções.

O sistema de elevação é composto pela torre (ou mastro), formada por uma série de tubos enroscados, que suporta o gancho e os elevadores e é sustentada por um conjunto de polias, denominado Catarina, além dos cabos de perfuração, outro bloco de polias, o de coroamento, e do guincho e seus motores.

Já o sistema de circulação é o encarregado de bombear a lama de perfuração.

Quando perfurando, as bombas de lama são utilizadas para circular os fluidos dos tanques de fluidos de perfuração, através do tubo bengala, mangueiras de perfuração, swivel, haste quadrada, tubulação de perfuração, até a broca. Assim, os cascalhos oriundos do corte das formações, pela broca, são carregados do fundo do poço para a superfície. (CORRÊA, 2003, p. 31)

As bombas de lama desse sistema ainda são utilizadas na cimentação, durante o revestimento do poço para evitar que o poço desmorone e auxiliar na circulação dos fluidos de perfuração.

Com relação ao último sistema essencial, o de rotação, ele é o responsável pela perfuração rotativa e constituído, basicamente, pela mesa rotativa e seus motores, a haste quadrada e o swivel. Os motores podem ser a explosão ou elétricos.

Por fim, o preventor de erupções é constituído por um conjunto de válvulas de alta pressão, colocadas uma em cima da outra e fixadas com parafusos, que previnem e agem durante uma erupção de gás, óleo, água ou outros fluidos que possivelmente cheguem à superfície. Quando há o alerta ou a erupção é constatada, o sistema fecha o poço e desvia os fluidos, primeiramente, para um tanque de lama reserva, depois para um desgaseificador e depois para os tanques de lama, onde serão armazenados. Neste equipamento, a lama com peso e densidade menor tem a possibilidade de ser tratada para elevar seu peso ou mudar suas características. 
No mais, com os testes, aqui já citados, que são realizados com os cascalhos durante a perfuração é possível se obter o perfilhamento da área e se constatar realmente a existência ou não de hidrocarbonetos e se tal reserva é viável.

Para definir a real produtividade do poço, pode ser programado um teste de formação de longa duração (cerca de 72 horas). Esses testes são feitos co uma coluna, na qual colocam-se dois packers (vedadores de borracha infláveis, sob pressão), para isolar o intervalo a ser testado, tendo entre elas uma de tubos perfurados, por onde penetrará o fluido da formação, quando se abrir uma válvula que permite a entrada dos fluidos para dentro da tubulação e, em alguns casos, conforme o programado, surgindo na superfície, onde será direcionado para tanques para tal fim. (CORRÊA, 2003, p. 44)

Vale ressaltar, mais uma vez, que tais estudos também são importantes para o conhecimento da área, não perdendo o valor depois da descoberta de hidrocarbonetos ou não.

Caso o poço apresente-se seco, o revestimento que vinha sendo feito por fase é estacionado e são descidas pastas de cimento (tampões), uma por vez, para o fechamento do poço e assim não permitir a circulação de fluidos de algumas áreas. Segundo Corrêa, o número de tampões varia conforme a quantidade de zonas que necessitam de isolamento.

Em campos já em desenvolvimento podem ser perfurados outros poços, além dos já comentados.

Tais poços podem ter a inclinação o mais próximo possível da horizontal: são os poços horizontais. Essa característica, consoante Corrêa, aumenta "a exposição da zona produtora em $100 \%$, pois a parte final do poço fica totalmente envolvida pelo reservatório. Esse tipo de poço está em grande evidência nos últimos anos."

Esse tipo de poço faz parte de um grupo denominado de poços direcionais, que proporcionam a base de perfuração, na superfície, atingir pontos muito distantes e de difícil acesso.

As situações que necessitam de tais poços são:

- objetivos longe da locação;

- perfuração dentro de vilas e cidades;

- na beira de rios, lagos e do mar;

- afastamento de poços secos;

- plataformas com múltiplos poços;

- interferir em poços com blowouts; e outros.

O desvio de poções é feito por ferramentas especiais como: turbinas; calhas desfiaduras; subs defletores (knuckle joints); brocas com jatos especiais; comandos não magnéticos ( $k$ monel), etc. Para conseguir-se o desvio do poço, utiliza-se uma ou mais dessas ferramentas e efetua-se um preciso controle dos parâmetros de perfuração $e$, principalmente, do posicionamento dos estabilizadores na coluna de comandos. (CORRÊA, 2003, p. 47)

A fim de se manter o controle da orientação do poço, no que diz respeito à direção e 
inclinação, são retiradas fotos, por meio de equipamentos especiais, que registram continuamente - o que permite a tomada correta de decisões a qualquer momento, como a alteração de parâmetros ou a retirada da tubulação para modificar a distribuição dos estabilizadores da coluna, tudo isso para o poço chegar a seu objetivo.

\title{
3. PRODUÇÃO DE PETRÓLEO
}

Poços são os condutos para o fluxo dos fluidos das formações até a superfície. Para mantimento e o controle desse fluxo são utilizados equipamentos e vários itens, denominados, conforme Corrêa (2003, p. 51), de "completação de poço".

Como as situações se tornaram mais complexas, sendo necessárias completações cada vez mais profundas para que aumentassem as zonas produtoras, inúmeros equipamentos de fundo de poço foram desenvolvidos. Devido à evolução na tecnologia de cimentação, ela pode ser usada como recurso na compleação:

\begin{abstract}
A cimentação de um poço é uma operação essencial em todas as completações, pois é necessária uma boa aderência do cimento no espaço entre o revestimento e a formação produtora (reservatório). Atualmente, a maioria dos poços são cimentados cobrindo todo o reservatório e cobrindo uma certa altura acima do topo do mesmo. (CORRÊA, 2003, p. 51)
\end{abstract}

A fim de estabelecer-se o fluxo para os poços, bem como sua estimulação, uma vez que a produção tende a diminuir no decorrer do tempo, fazem-se furos laterais, ou perfurações, com cargas explosivas dirigidas, equipamento vulgarmente conhecido por "canhão"; com ácido para um fraturamento hidráulico; ou com a diminuição da tubulação, o que Corrêa $(2003$, p. 51) denomina tubing, com a finalidade de tornarem viáveis a velocidade, a pressão e o volume produzido; entre outros.

São variadas as opções de mecanismos de produção de petróleo e/ou gás que podem ser utilizados para levar os fluidos do fundo do poço até a superfície.

Quando a pressão do reservatório é suficiente para tal fim, o poço é considerado surgente. Caso seja necessário fornecer alguma energia auxiliar no interior do poço, a surgência é dita artificial.

Há vários sistemas de elevação artificial que auxiliam o poço a conseguir atingir a vazão esperada. Entre estes sistemas, temos os seguintes:

- Bombeio mecânico por hastes (sucker rod pumping);

- Elevação por gás (gás lift);

- Bombeio elétrico submerso convencional (electrical submersible pumping);

- Bombeio elétrico a pistão (hydraulic piston pumping);

- Bombeio hidráulico a jato (hydraulic jet pumping);

- Elevação a embalo (plunger lift); 
- E outros. (CORRÊA, 2003, p. 56)

Na região de Alto do Rodrigues/RN, localizado no vale do Açu, durante visita técnica, o grupo observou grande proporção do mecanismo de elevação artificial de bombeio mecânico, cuja bomba é conhecida como "Cavalo de pau", como pode ser observado na figura abaixo (figura 1) com destaque para dois desses mecanismos de bombeio:

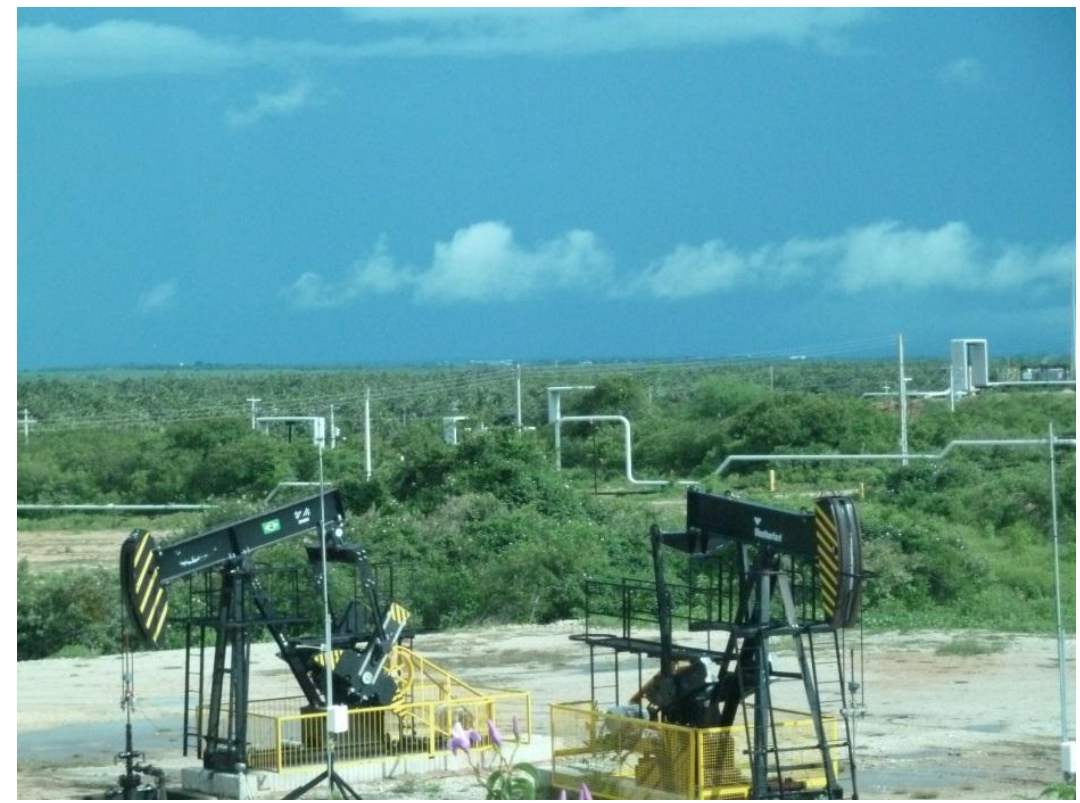

Figura 1: “Cavalos de Pau” utilizados na exploração de poços em Alto do Rodrigues (RN). Fonte: Nova (2011).

O bombeio mecânico é uma unidade motora instalada na superfície, que aciona as hastes controladoras da bomba, e que por um movimento de pistoneio do poço, devido ao movimento alternado das hastes, o óleo é produzido. Podem-se observar as seguintes vantagens e desvantagens:

Vantagens:

- Pode usar gás ou eletricidade como fonte de energia;

- Simples e fácil de operar;

- Aplicável em poços de pequeno diâmetro e completações múltiplas;

- Pode bombear um poço com baixa pressão;

- Pode elevar óleos de alta temperatura e viscosidade.

Desvantagens:

- Poços tortuosos apresentam problemas de fricção;

- Alta produção de sólidos causa problemas; 
- É limitado pela profundidade, devido, principalmente, à capacidade das hastes;

- Obstrui em locações urbanas;

- Pesado e volumoso para operações no mar. (CORRÊA, 2003, p. 57)

\section{IMPACTOS AMBIENTAIS DE EXTRAÇÃO DO PETRÓLEO}

A sustentabilidade está ligada ao desenvolvimento tecnológico e econômico sem agressão ao meio ambiente, usando os recursos naturais de maneira inteligente, possibilitando a manutenção deles (rios, lagos, oceanos, florestas, matas) e garantindo a existência de vida no futuro. Sendo assim, cada atividade realizada pelo ser humano deve levar em consideração primeiramente a sustentabilidade, tornando sustentável o desenvolvimento, com ações que possam suprir as necessidades humanas e sejam socialmente justas, ambientalmente corretas e economicamente viáveis, resguardando as gerações futuras.

É indubitável que a extração do petróleo gera impactos ambientais e sociais tanto diretamente quanto indiretamente. Uma vez que essa atividade se constitui na intervenção do meio ambiente para extração de um recurso natural, com potenciais impactos ambientais. Por outro lado, os impactos podem ser positivos, através do aumento da arrecadação tributária e um aumento no dinamismo econômico da região. Por isso, cabe a análise cuidadosa do que é mais vantajoso tanto para o meio ambiente quanto para a sociedade, sob a ótica da sustentabilidade.

Impacto ambiental é qualquer alteração (vantajosa ou danosa) no meio ambiente causada por determinada ação ou atividade que afete a qualidade do solo, água, atmosfera (meio físico), dos ecossistemas, da flora, ou da fauna (meio biótico) ou das atividades humanas como turismo, pesca ou atividades culturais (meio socioeconômico).

Os impactos podem vir a atingir os diversos níveis de organização dos seres vivos desde o subcelular até o ecossistema. Uma modificação em níveis mais baixos pode ou não ser refletida em níveis superiores como uma diminuição na biodiversidade ou modificação (negativa ou positiva) no patrimônio genético. Sendo de extrema importância a análise da estrutura e das interações dos organismos que serão afetados com a mineração.

A água contaminada apresenta-se como um dos principais impactos ambientais da produção de petróleo. Essa contaminação ocorre ao tentar manterem-se condições adequadas de pressão na rocha-reservatório para a migração do petróleo até a superfície; no processo geralmente é efetuada uma injeção de água nas camadas inferiores do reservatório. Conforme Cotovicz Junior e Silva (2009, p. 91, apud MARIANO; ROVERE 2006) "um campo novo produz de 5 a $15 \%$ de volume de água. À medida que a vida econômica dos poços se esgota, essa água pode atingir uma faixa de 75 a $90 \%$ de volume total extraído do poço".

A água produzida na exploração do petróleo contém geralmente alta salinidade, partículas de óleo em suspensão, produtos químicos adicionados nos diversos processos de produção, metais pesados e por vezes alguma radioatividade. Isto a torna um poluente de difícil descarte agravando-se pelo expressivo volume e quantidade de compostos envolvidos. (COTOVICZ JUNIOR; SILVA 2009, p. 94 apud RAY; ENGELHARDT, 
1992)

A produção excessiva de água descartada é um problema sério nos campos de petróleo maduros. Geralmente o descarte é feito em grandes ambientes receptores (áreas offshore), onde a diluição e a dispersão rápida tomam lugar. O descarte de tais volumes de resíduos vem causando preocupações sobre a poluição ambiental não controlada e irreversivel no ambiente marinho. As águas produzidas apresentam, em geral, altos teores de contaminantes tóxicos; produtos químicos adicionados durante a injeção, além de uma complexa mistura de complexos orgânicos e inorgânicos dependendo do campo petrolifero. $O$ impacto ambiental é avaliado pela toxicidade dos constituintes e pela quantidade dos compostos presentes. (COTOVICZ JUNIOR; SILVA, 2009, p. 94 apud LIMA et al., 2008)

Devido aos grandes danos ambientais gerados pela água descartada no processo, a legislação atuou de modo a estabelecer limites de contaminantes. A resolução do CONAMA 357/05 estabelece níveis aceitáveis de hidrocarbonetos e outros contaminantes para o descarte de águas utilizadas no processo de extração do petróleo. 0 artigo 24 dessa resolução estabelece como a concentração padrão para o lançamento de efluentes o limite de $20 \mathrm{mg} / \mathrm{l}$ por dia.

\section{PETRÓLEO NO RN: HISTÓRIA}

A descoberta do petróleo no Rio Grande do Norte foi de fundamental importância, uma vez que, em solo potiguar, foram feitos os primeiros registros de indícios do chamado "ouro negro" em território brasileiro. A descoberta foi feita ainda no final do século XIX pelo padre Florêncio Gomes, no município de Apodi.

Entretanto, passaram-se décadas desde o primeiro registro até a confirmação da existência de petróleo no Rio Grande do Norte, pois foi necessário que vários pesquisadores e pessoas influentes insistissem que na bacia potiguar havia petróleo.

Cientificamente, as primeiras afirmações da existência de petróleo são do geólogo norteamericano John Casper Branner, que em 1922 publicou um livro, no qual indicava a possibilidade de haver petróleo na região de Mossoró.

Quase uma década depois, em 1956, a Petrobras resolveu fazer a primeira sondagem no Rio Grande do Norte, na região de Gangorra, município de Grossos. Embora tenham confirmado a existência de petróleo e de gás natural, os estudos concluíram por uma inviabilidade econômica.

Em 1966, o prefeito de Mossoró contratou uma firma para abrir um poço d'água, supervisionado pelo geólogo Lúcio Cavalcante, na praça Pe. João Mota. O poço jorrou petróleo misturado com água e serviu de combustível para as lamparinas da população pobre "durante meses". Vinte anos depois, quando alguns estados já produziam petróleo com sucesso, foi descoberto o campo marítimo de Ubarana, em Macau-RN.

Porém, foi apenas em 1973 no contexto da primeira crise do petróleo, que a Petrobras reiniciou suas pesquisas, esta feita na plataforma continental confrontante com os municípios de Macau e Guamaré, descobrindo o campo petrolífero de Ubarana.

Dessa forma, em 1974, chegou a primeira plataforma continental na costa do município de Macau. Um ano depois, o poço marítimo RNS-3 estava em pleno funcionamento. Inclusive o presidente na época, Ernesto Geisel, veio visitá-lo. 
A partir de 1975, a Petrobras começou a perfuração de poços na cidade de Mossoró. Entretanto foi apenas em 1979 que encontraram petróleo em poços de água. O poço MO-13 deu origem ao campo de Mossoró, ainda no ano de 1979. Em 1980, foi perfurado o poço Mossoró-14, que foi o primeiro poço terrestre comercialmente viável do Rio Grande do Norte.

Na década de 1980, a perfuração de poços petrolíferos terrestres foram intensificadas nos municípios de Macau, Mossoró, Areia Branca e Alto do Rodrigues. A reestruturação das atividades de exploração, perfuração e produção no RN foi feita pela Petrobras no ano de 1995.

Até o ano de 2003, já havia 4664 poços produtores de petróleo, que tinham uma produção diária de 85 mil barris, conferindo ao Estado a posição de o 1으 maior produtor em terra e o 20 maior produtor em mar do Brasil.

\section{EXPLORAÇÃO NO RN: ALTO DO RODRIGUES}

A bacia potiguar compreende uma área de $22.500 \mathrm{~km}^{2}$, segundo o Serviço Brasileiro de Apoio às Micro e Pequenas Empresas (SEBRAE) (2005, p. 70), de terras emersas, limitando-se ao sul, leste e oeste com rochas do embasamento cristalino e ao norte com o oceano atlântico e com 0 alto de Fortaleza.

É sem dúvida uma importante fonte de recurso, como pode-se observar com os dados da Agência Nacional do Petróleo (ANP) de 2008, onde o RN produziu 22.331.784 barris, dos quais 19.207.588 extraídos em terra e ainda apresentou a produção diária, segundo dados do SEBRAE (2005, p. 75), de três (03) milhões de $\mathrm{m}^{3}$ de gás natural, sendo considerado o maior produtor nacional de petróleo em terra e o segundo no mar, atrás apenas do Rio de Janeiro, na época.

O SEBRAE (2005, p. 70) nos traz a informação de que "a bacia desenvolveu-se sobre um substrato de rochas pré-cambrianas. Seu arcabouço estrutural é constituído basicamente por quatro feições morfo-estruturais, relacionadas com o contexto evolutivo da margem equatorial atlântica, iniciada no final do período Jurássico."

No ano 2000, a Petrobras, construindo uma segunda unidade de processamento de gás natural em Guamaré, dobrou a produção de gás no estado, além de também, passar a produzir diesel e nafta no território potiguar.

Ao se falar da importância dos royalties para as receitas municipais, tal representatividade chega, em alguns municípios, a mais de $50 \%$ do total do orçamento municipal, conforme SEBRAE (2005, p. 79). Ainda dialogando com $\operatorname{SEBRAE}(2005$, p. 79): o volume total dos recursos repassados sob a forma de royalties ao Estado, em 2004, foi superior a $\mathrm{R} \$ 276$ milhões. Desses recursos, cerca de $36 \%$, ou seja, $\mathrm{R} \$ 98$ milhões, foram repassados diretamente aos quinze municípios produtores de petróleo e/ou gás natural.

\subsection{Caracterização da área}

Alto do Rodrigues é um município norte rio-grandense, situado a $236 \mathrm{~km}$ da capital do Estado, Natal, na mesorregião do Oeste Potiguar e microrregião do vale do Açu. As fronteiras municipais são estabelecidas com Carnaubais, Pendências, Afonso Bezerra e Açu, o que diz respeito a uma área de $207 \mathrm{~km}^{2}$, como pode ser observado no mapa abaixo (figura 2), com 
destaque para Alto do Rodrigues e a bacia hidrográfica do rio Piranhas Açu:

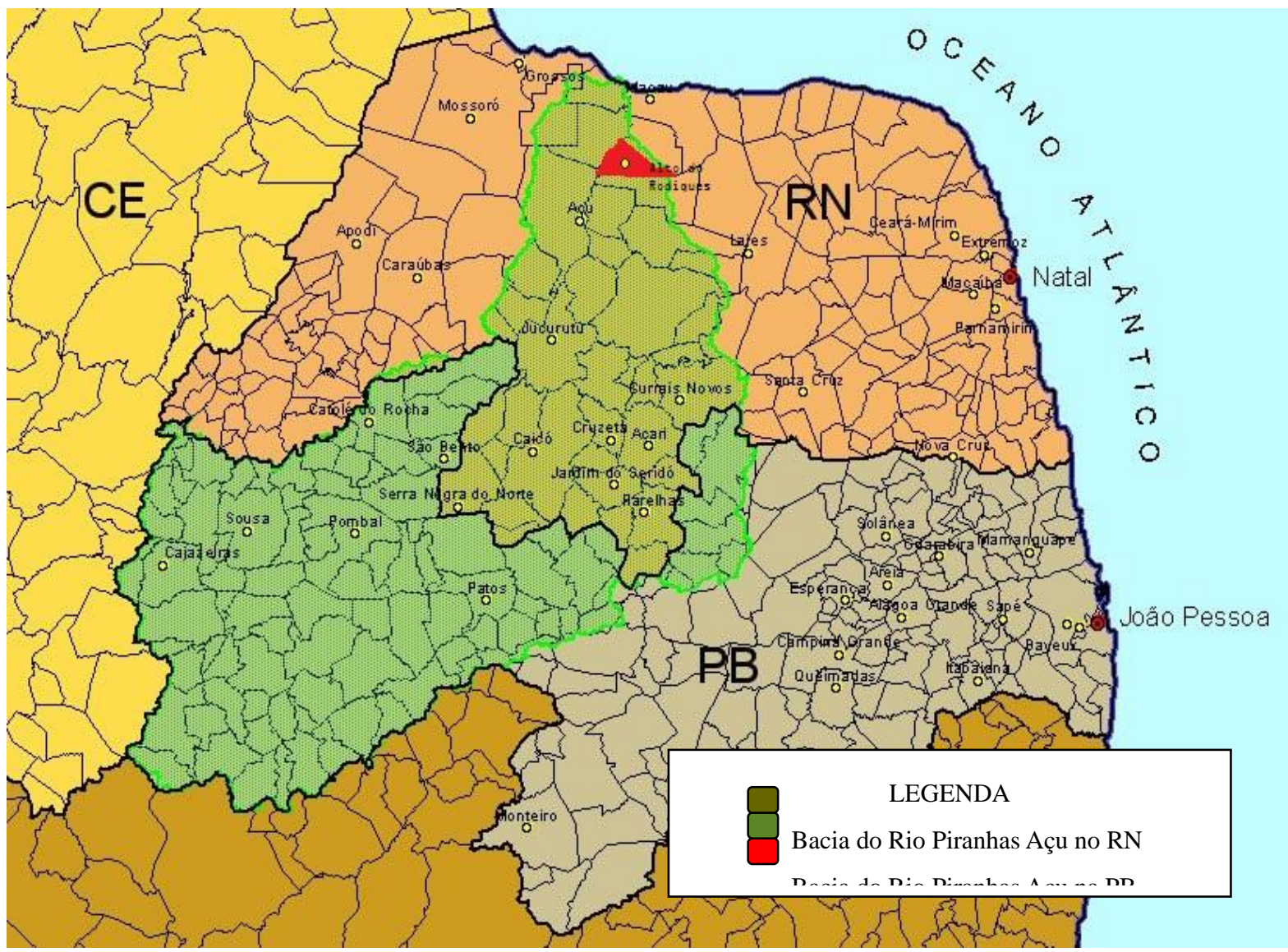

Figura 2: Mapa do Rio Grande do Norte com destaque, segundo legenda, para o município de Alto do Rodrigues e a bacia do rio Piranhas Açu. Fonte: Gurgel, Queiroz, Santos, Galvão (2012), adaptado de Moura (2007).

Segundo Serviço Geológico do Brasil (2005, p. 03), as principais atividades econômicas do município são: agropecuária, extração de petróleo, gás natural, comércio e extrativismo. Ainda consoante o Serviço Geológico do Brasil (2005, p. 04), Alto do Rodrigues possui temperatura média anual em torno de 25 ㄷ C umidade relativa média anual de $69 \%$, além do clima quente e semi-árido, o que provoca uma grande evaporação e concentração de sais na parte superficial do solo - sais esses que aparecem devido à proximidade com o mar.

Com relação à formação geológica, temos a citação de Serviço Geológico do Brasil (2005, p. 04): o município de Alto do Rodrigues encontra-se inserido, geologicamente, na Província Borborema, sendo constituído pelos sedimentos das formações Jandaíra, Tibau do Grupo Barreiras e dos Depósitos Aluvionares.

\subsection{Utilização do gás natural}

A primeira vez que o gás natural foi usado no mundo aconteceu a cerca de 300 anos, na China, em que um vazamento superficial possibilitou sua coleta, através de tubulações de 
bambus, para ser queimado e utilizado na evaporação de água salgada a fim de se obter sal.

Esse gás é composto essencialmente pó hidrocarbonetos leves em estado gasoso, como metano, etano e propano; mas ainda podem existir contaminações por nitrogênio, dióxido de carbono, água e compostos de enxofre. Ele normalmente é encontrado nos reservatórios, sendo acompanhado, ou não, por petróleo. Quando vem acompanhado de petróleo, essa relação depende do grau de saturação do óleo com gás, em outras palavras, a quantidade de gás que está dissolvido no óleo.

O gás possui um poder calorífico de $9.400 \mathrm{kcal} / \mathrm{m}^{3}$. A energia disponibilizada é, provavelmente, o maior meio de transporte do óleo dos reservatórios. Se existir gás dissolvido no óleo, sua viscosidade diminui, tornando mais fácil sua produção. Ele é inodoro, incolor e asfixiante, sendo assim, por medida de segurança, é adicionado composto de enxofre a fim de que o odor permita identificar vazamentos.

O volume de gás que permanece em solução nos reservatórios, depende da pressão e da temperatura do mesmo. Quando no reservatório, há menos gás do que o volume de óleo existente é capaz de absorver, o óleo é chamado de subsaturado e, no caso contrário, é chamado de supersaturado. Algum gás tende a se acumular nas estruturas mais altas do reservatório e formam uma capa de gás e, neste caso, o óleo permanece saturado com gás em solução. (CORRÊA, 2003, p. 16, grifo do autor)

Atualmente, o gás natural é terceira fonte de energia primária utilizada como matriz energética no mundo. Sua maior contribuição se dá pelo fato de apresentar uma queima uniforme, não produzindo resíduos, e assim não agredindo o meio ambiente. Conforme o SEBRAE (2003, p. 22) sob condições normais de temperatura e pressão, $1.000 \mathrm{~m}^{3}$ de gás equivalem a uma tonelada de petróleo.

Tal fonte energética é transportada comumente através de dutos em seu estado gasoso, mas também pode ser transportado por caminhões, trens e navios, sendo que dessa forma ele precisa ser pressurizado e acondicionado em cilindros (Gás Natural Comprimido - GNC) ou ser liquefeito (Gás Natural Liquefeito - GNL), o que reduz seu volume em 600 vezes.

No entanto, não é só como fonte energética que o gás natural se destaca. Ele também é utilizado como matéria-prima na obtenção de vários produtos, e a partir desses chegar a outros de grande importância comercial como os combustíveis:

Produtos primários: acetileno, formaldeído, metano, proteína sintética, negro e fumo, enxofre elementar, etileno e amônia.

Produtos secundários: a partir do acetileno - benzeno, neoprene, ácido acético e acrinolitilas; a partir do formaldeído - desinfetantes e plásticos; a partir do metano metanol, hidrogênio e cloreto de metila; a partir do fumo negro - pneumáticos; a partir do enxofre - anidrido sulfuroso; a partir do etileno e da amônia - explosivos, ácido nítrico, fertilizantes, polímeros, etileno glicol.

Produtos terciários: a partir da acrinolitilas - fibras acrílicas e elastômeros de nitrila; a partir do hidrogênio - combustíveis; a partir do cloreto de metila - tetracloreto de carbono; a partir do anidrido sulfuroso - ácido sulfúrico, preservativos de alimentos, alvejantes industriais, dissulfeto de carbono. (SEBRAE 2005, p. 22, grifo do autor)

O Rio grande do Norte participa com $8 \%$ do volume total de reservas provadas de gás natural nos estados, segundo dados de 2003 da Associação Nacional do Petróleo (ANP), o que 
corresponde a $20.440 \mathrm{~m}^{3}$.

\subsection{TERMOAÇU}

No dia 15 de junho de 2011, a usina termoelétrica do vale do Açu, Jesus Soares Pereira, permitiu uma visita técnica a suas instalações e colheita de dados sobre a empresa e seu processo produtivo. Somente foi autorizada a retirada de uma fotografia das caldeiras e chaminés da usina (figura 3), como pode ser observado a seguir:

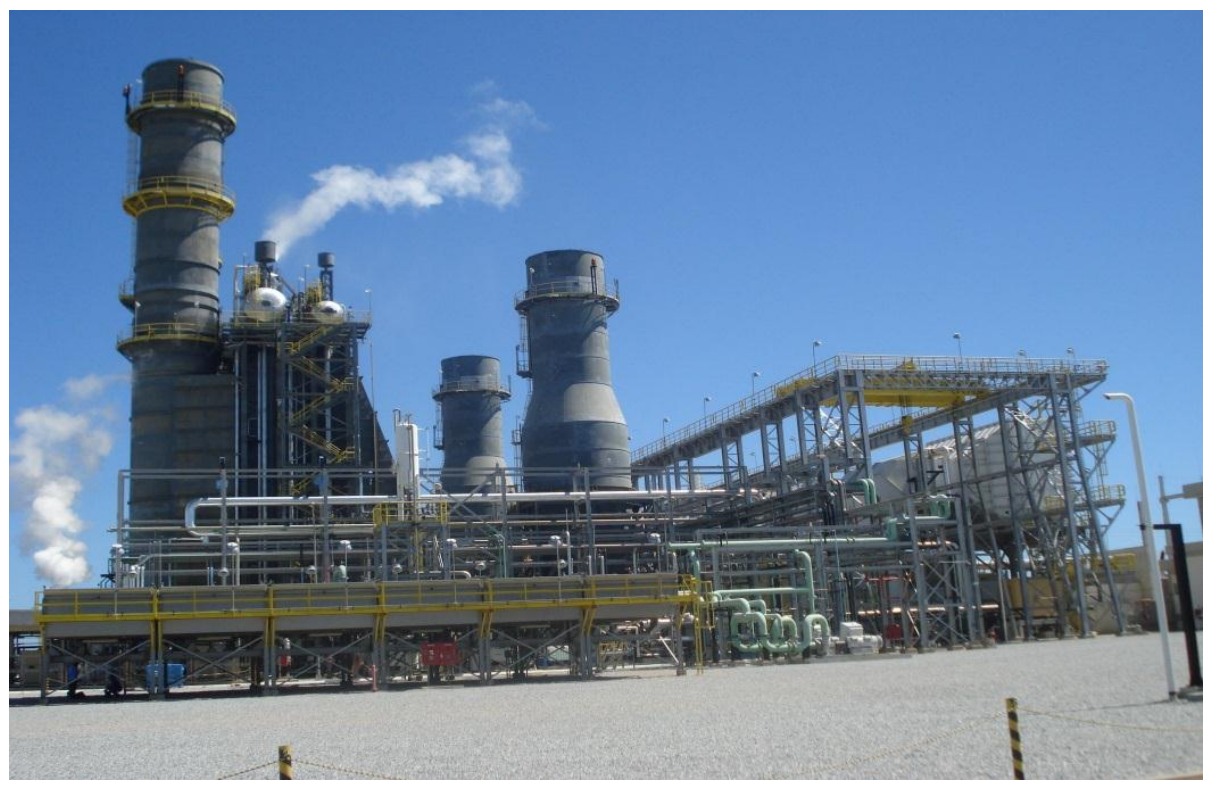

Figura 3: Caldeiras e chaminés da Termoaçu, Alto do Rodrigues (RN). Fonte: Gurgel, Queiroz, Santos, Galvão (2011)

Para transmitir os dados e informações a empresa disponibilizou um de seus engenheiros. Segundo o mesmo, a usina foi inaugurada no dia 19 de setembro de 2008 com investimentos da Petrobras (80\%) e do grupo Iberdrola (20\%), sendo que atualmente essa última parte está alugada a primeira empresa. Ela é uma usina de co-geração, ou seja, é capaz de produz, simultaneamente, energia elétrica e térmica (calor/vapor do processo). A Petrobras fornece o gás natural utilizado como fonte de energia na usina. Em contra partida, a usina vende vapor de água para a mesma, que o utiliza a fim de ajudar na fluidez do óleo dos poços durante o bombeamento, prática inovadora e ainda pouco difundida no mundo. O vapor de água produzido é determinado pela demanda.

Conforme o engenheiro, a usina é capaz de suprir mais da metade da necessidade energética do estado potiguar, e exporta energia para atender clientes da Companhia Elétrica da Bahia (Coelba) e Argentina. A energia que é produzida vai para o sistema de distribuição, que no caso é a Companhia Hidro Elétrica do São Francisco (CHESF), e de lá é direcionada para onde é requerida. A demanda energética é determinada por esse sistema. No dia da visita, por exemplo, a usina estava produzindo $130 \mathrm{MW}$. Ela é capaz de produzir $370 \mathrm{MW}$, consoante o funcionário. Em tempos de pouca demanda, a usina produz no mínimo $90 \mathrm{MW}$, para garantir a sustentabilidade 
da prática. Quando a demanda for menor que $90 \mathrm{MW}$, a termoelétrica produzirá apenas $30 \mathrm{MW}$, para suprir a necessidade da Petrobras de vapor de água - a usina é capaz de produzir $450 \mathrm{t} / \mathrm{h}$ de vapor de água.

A usina não produz gases tóxicos ou do efeito estufa, devido à eficiência no processo de combustão utilizado por eles, além de ser mais viável a queima de gás de que a queima de qualquer outro combustível segundo o engenheiro - eles não possuem filtro nas chaminés devido a esse fato, sendo o vapor de água produzido destinado à atmosfera. A usina também tem uma estação de tratamento, que devolve, com melhores parâmetros, a água do rio Açu utilizada nas caldeiras - em outro ponto diferente do da coleta.

Essa água que é coletada passa por uma grade, que retém os sólidos de grande diâmetro, por um filtro, vai para a floculação e recebe substâncias para ficar deionizada. Depois do processo, ela se mistura ao óleo e aos outros e efluentes advindos do processo e das dependências da empresa, para então ser separada e cada um receber um tratamento. Ela retorna ao rio quase em sua totalidade, pois há uma parte perdida na combustão e em vapor de água.

Os lodos produzidos na estação de tratamento, bem como os resíduos, são colocados em caçambas e a Petrobras é a encarregada da destinação final - que o engenheiro afirmou ser um aterro sanitário.

Um problema que há na usina é o excesso de aves, que usam a estrutura da empresa como abrigo e acabam depositando fezes e penas nela, o que acarreta em problemas na saúde nos funcionários.

Os riscos que há na empresa, segundo o encarregado, são: os ruídos, as altas temperaturas e pressões (riscos físicos), que podem se agravar em casos de acidente - mas não afetam a população devido a localização do empreendimento -; os compostos de petróleo, o gás e as substâncias utilizadas no tratamento de águas e efluentes, como o ácido sulfúrico (riscos químicos); e os esgotos, além dos lodos provenientes da estação de tratamento de água e as aves (riscos biológicos) - não houve problemas com outros animais (de grande porte).

\section{CONSIDERAÇÕES FINAIS}

É incontestável a importância da atividade petrolífera no Rio Grande do Norte, uma vez que ela proporciona através de royalties, geração de empregos e melhoria de infra-estrutura, entre outros pontos, um desenvolvimento tanto econômico quanto social do estado. Entretanto, como a atividade demonstra aspectos agressivos aos recursos naturais, a busca por tecnologias que auxiliem o desenvolvimento cada vez mais sustentável não deve cessar.

Nessa perspectiva, a demonstração do surgimento e desenvolvimento da atividade, a composição do produto, bem como a abordagem localizada no Rio Grande do Norte e a possibilidade de atividades atreladas, como a utilização do gás, extraído junto com o óleo, para a produção energia elétrica, exemplificam como a atividade petrolífera é impactante para o meio ambiente, mas em contra partida não descartam o petróleo como valioso recurso, uma vez que são enormes os benefícios trazidos para a região, como produção e consumo, royalties nas pequenas economias regionais, a consciência ambiental praticada por meio da educação da população e das empresas de petróleo e gás, entre outros, sendo importante a constante busca 
por medidas mitigadoras enquanto se explora esse recurso.

A pesquisa encontra-se em desenvolvimento, mas os primeiros frutos que se tem do trabalho são a perspectiva de que a atividade petrolífera demanda estudos a fim de que se diminuam ou mitiguem os danos ambientais, que muitas vezes se configuram em cadeia, bem como é de extrema importância sua continuidade para o desenvolvimento do país uma vez que esse recurso tão valioso é almejado por todo o mundo.

\section{REFERÊNCIAS}

1. CORRÊA, O. L. S. Petróleo: noções sobre exploração, perfuração, produção e microbiologia. Rio de Janeiro. Interciência, 2003.

2. GURGEL, C. A. V.; QUEIROZ, G. B. de; SANTOS, E. L. S. C. Dos; GALVÃO, M. L. de M. Fotos da TERMOAÇU. Alto do Rodrigues, 2011. 01 fotografias.

3. _. Mapa adaptado de Alto do Rodrigues. Natal, 2012. 01 mapa.Serviço Geológico do Brasil. Projeto Cadastro de Fontes de Abastecimento por Água Subterrânea: estado do Rio Grande do Norte. Recife: CPRM/PRODEEM, 2005.

4. CÚNEO, Roberto Grillo. Petróleo. Disponível em: <http://www.algosobre.com.br/quimica/petroleo.html>. Acesso em 19 jan. 2011.

5. COTOVICZ JUNIOR, L. C.; SILVA, V. P. da. Licenciamento ambiental onshore no Rio Grande do Norte: uma análise do descarte da água produzida em relatório de controles ambientais. In: PEGADO, É. A. da C.; SILVA, V. P. da (Org.). Licenciamento ambiental onshore: limites e otimização. Natal: IFRN, 2009, p. 89-114.

6. FORMAÇÃO do petróleo. Guia do estudante: Geografia, São Paulo, Ed. 04, p. 39, jan. 2011. Anual.

7. MOREIRA, João Carlos; SENE, Eustáquio de. Geografia: ensino médio. Vol. Único. São Paulo: Scipione, 2005.

8. SERVIÇO BRASILEIRO DE APOIO ÀS MICRO E PEQUENAS EMPRESAS (SEBRAE). Petróleo e gás no Rio Grande do Norte: prospectando negócios. Natal: SEBRAE/RN, 2005.

9. SERVIÇO GEOLÓGICO DO BRASIL. Projeto cadastro de fontes de abastecimento por água subterrânea: estado do Rio Grande do Norte. Recife: CPRM/PRODEEM, 2005.

10. SOUSA, R. História do petróleo no Brasil. Disponível em: <http://www.brasilescola.com/brasil/historia-do-petroleo-no-brasil.html>. Acesso em: $02 \mathrm{dez}$. 2010. 